\title{
On the role of traditional ecological knowledge as a collaborative concept: a philosophical study
}

Kyle Powys Whyte

\begin{abstract}
Introduction: The concept of traditional ecological knowledge (TEK), along with synonymous or closely related terms like indigenous knowledge and native science, has some of its origins in literatures on international development and adaptive management. There is a tendency to want to determine one definition for TEK that can satisfy every stakeholder in every situation. Yet a scan of environmental science and policy literatures reveals there to be differences in definitions that make it difficult to form a consensus. What should be explored instead is the role that the concept of TEK plays in facilitating or discouraging cross-cultural and cross-situational collaboration among actors working for indigenous and non-indigenous institutions of environmental governance, such as tribal natural resources departments, federal agencies working with tribes, and co-management boards.
\end{abstract}

Methods: This is a philosophical paper that explores how the concept of TEK is defined in science and policy literatures and what purpose it serves for improving cooperative environmental and natural resources stewardship and management between indigenous and non-indigenous institutions. The philosophical method applied here is one that outlines numerous possible meanings of a concept (TEK, in this paper) and the implications of each meaning for science and policy.

Results: In science and policy literatures, there are different definitions of TEK. Controversy can brew over TEK when people hold definitions that are based on different assumptions. There are two kinds of assumptions about the meaning of TEK. The first kind refers to assumptions about the mobilization of TEK, or what I call knowledge mobilization. The second kind involves assumptions about how to understand the relationship between TEK and disciplines like ecology or biology, or, in other words, the relation between TEK and science. Different positions that fall under the two kinds of assumptions (knowledge mobilization; TEK and science) can generate disagreements because they imply differences about "whose" definition of TEK gets privileged, who is counted as having expert authority over environmental governance issues, and how TEK should be factored into policy processes that already have a role for disciplines like forestry or toxicology in them.

Conclusions: In light such disagreements, I argue that the concept of TEK should be understood as a collaborative concept. It serves to invite diverse populations to continually learn from one another about how each approaches the very question of "knowledge" in the first place, and how these different approaches can be blended to better steward natural resources and adapt to climate change. The implication is that environmental scientists and policy professionals, indigenous and non-indigenous, should not be in the business of creating definitions of TEK. Instead, they should focus more on creating long term processes that allow the different implications of approaches to knowledge in relation to stewardship goals to be responsibly thought through.

Correspondence: kwhyte@msu.edu

Department of Philosophy, Michigan State University, 368 Farm Lane, \#503, East Lansing, MI 48824, USA

\section{空}

(c) 2013 Whyte; licensee Springer. This is an Open Access article distributed under the terms of the Creative Commons Attribution License (http://creativecommons.org/licenses/by/2.0), which permits unrestricted use, distribution, and reproduction in any medium, provided the original work is properly cited. 


\section{Introduction}

The concept of traditional ecological knowledge (TEK) comes up frequently in certain segments of environmental and natural resources science and policy literatures (Houde 2007). For some people, the term has come to refer to indigenous peoples ${ }^{\text {a }}$ legitimate systems of knowledge production. Such systems have empirically tested (and testable) understandings of the relationships among living things and their environments, though there may be notable differences with scientific approaches characteristic of disciplines like ecology or biology. The English language articulation of TEK-along with synonymous or closely related terms like indigenous knowledge (Brokensha et al. 1980) and native science (Cajete 1999)_originates in literatures on international development (Agrawal 1995; Warren et al. 1995) and adaptive management (Berkes 1999). It continues to show up regularly in science conferences, like the 97th Annual Meeting of the Ecological Society of America in 2012, which featured approximately 13 papers on TEK. It is also found increasingly in the plans and policies of government agencies, such as the Northwest Forest Plan (Harris 2011) and the Natural Resources Conservation Service (Leonetti 2010) in the U.S., and international regimes such as the United Nations Environmental Programme (UNEP 1998).

Examples of TEK in scientific and policy literatures are diverse. They range from historical practices like the creation of forest islands for the production of fruit and attraction of game (Gadgil et al. 1993), to currently practiced skill-based traditions like deer cleaning techniques embodying community value systems (Reo and Whyte 2012), to practical applications for natural resource management and climate change like burning practices (Kimmerer and Lake 2001) and observations of changes in water levels, sea ice, lake processes, and the movements of animal populations (Voggesser 2010; Wildcat 2009; Nakashima et al. 2012; Eisner et al. 2009).

Yet TEK is often invoked in ways that are controversial. There are three plausible reasons why this may be the case. (1) TEK often refers to knowledge production systems whose value has been overlooked or disapproved of by scientists and policy makers. Ignorance and disapproval are often tied to colonial, imperial, and other discriminatory attitudes and institutions of science toward “non-Western" knowledge systems (Harding 1998, 2011; Salmon 1996). (2) Definitions of TEK are often formulated by scholars or professionals who are not community members and hence have tendencies to privilege their own agendas for environmental and natural resources stewardship and management (McGregor 2008; Ellen 2000; Nadasdy 1999; Huntington 2000). (3) TEK is perceived as being a competing authority with science, creating divisions between indigenous expert authorities and scientific expert authorities (Kofinas 2005; McGregor 2008).
A good portion of this controversy revolves around a tendency to want to determine one definition for TEK that can satisfy every stakeholder in every context. Yet a scan of environmental science and policy literatures reveals there to be sufficiently large differences in definitions of TEK that may obstruct the possibility of moving toward a consensus on the best definition. These differences suggest an alternative direction for philosophical reflection on TEK. Perhaps what is important is not only defining TEK; rather, what should be additionally explored is the role that the concept of TEK plays in facilitating or discouraging cross-cultural and cross-situational collaboration between indigenous and non-indigenous institutions such as tribal natural resources departments, federal agencies working with tribes, and co-management boards.

I argue that the concept of TEK should be understood as a collaborative concept. It serves to invite diverse populations to continually learn from one another about how each approaches the very question of "knowledge" in the first place, and how these different approaches can work together to better steward and manage the environment and natural resources. Therefore, any understanding of the meaning of TEK is acceptable only so long as it plays the role of bringing different people working for different institutions closer to a degree of mutual respect for one another's sources of knowledge. The implication is that environmental scientists and policy professionals, indigenous and non-indigenous, should focus more on creating long term processes that allow for the implications of different approaches to knowledge in relation to stewardship and management priorities to be responsibly thought through.

The paper starts in the Methods section with a description of the philosophical method used to make the argument just mentioned. In the Results and Discussion section, I cover some of the different assumptions that make it hard for consensus to form on what TEK means. The subsection "TEK and knowledge mobilization" describes assumptions about knowledge mobilization; the subsection "The relation between TEK and science" describes assumptions about the relation between TEK and disciplines like ecology or biology. The subsection "The role of TEK as a collaborative concept" shows why TEK should be considered as a collaborative concept that bridges cross-cultural and cross-situational divides. The "Conclusions" section ends the paper with thoughts on the implications for cooperative environmental and natural resources stewardship and management. From now on, I will refer to environmental and natural resource stewardship and management as simply environmental governance.

\section{Methods}

This is a philosophical paper (written by an environmental philosopher) that explores how the concept of TEK is 
defined in science and policy literatures and what purpose it serves for improving cooperative environmental and natural resources stewardship and management between indigenous and non-indigenous institutions. The philosophical method applied here is one that outlines numerous possible meanings of a concept (TEK, in this paper) and the implications of each meaning for science and policy. The argument about TEK as a collaborative concept intends to spur greater reflective discussion among the relevant audiences on the meaning of a concept that may be controversial or simply taken for granted. This paper attempts to complement the scientific papers in this special issue of Ecological Processes.

\section{Results and discussion}

In science and policy literatures, there are different definitions of TEK. Controversy can brew over TEK when people hold definitions that are based on different assumptions. There are two kinds of assumptions about the meaning of TEK. The first kind refers to assumptions about the mobilization of TEK, or what I call knowledge mobilization. Knowledge mobilization refers to assumptions about what different types of knowledge can be used for and their adaptability to suit different contexts. The second kind involves assumptions about how to understand the relationship between TEK and disciplines like ecology or biology, or, in other words, the relation between TEK and science. The two kinds of assumptions (knowledge mobilization; TEK and science) can generate controversy because they imply differences about "whose" definition of TEK gets privileged, who is counted as having expert authority over environmental governance issues, and how TEK should be factored into policy processes that already have a role for disciplines like forestry or toxicology in them. The section "TEK and knowledge mobilization" begins to discuss these assumptions, starting with knowledge mobilization. The section "The relation between TEK and science" begins the discussion on the second kind of assumption (the relation between TEK and science).

\section{TEK and knowledge mobilization}

Some definitions see TEK as a basic body of knowledge. According to Nakashima et al., TEK is "the knowledge of Native people about their natural environment" (Nakashima 1993, 99). This basic body of knowledge is usually defined as having been gathered across generations: "Indigenous or traditional knowledge refers to the knowledge and know-how accumulated across generations, and renewed by each new generation, which guide human societies in their innumerable interactions with their surrounding environment" (Nakashima et al. 2012, 8). Definitions like this emphasize TEK as a substantive body of knowledge that is created and stored by human societies to aid in their flourishing in the face of environmental and natural resources challenges. The time scale of this knowledge is many generations. In this sense, TEK is taken as archival in nature. It is a store of knowledge of the relationships between living things and their environment.

A key assumption about knowledge mobilization in this definition is that TEK is a supply of knowledge ready to hand to be used by people in different contexts. In the policy document, Weathering Uncertainty: Traditional Knowledge for Climate Change Assessment and Adaptation (United Nations), Nakashima et al. write that such "community-based and local knowledge may offer valuable insights into environmental change due to climate change, and complement broader-scale scientific research with local precision and nuance" (2012, 6). They go on to state, as an example, that "Indigenous observations and interpretations of meteorological phenomena have guided seasonal and inter-annual activities of local communities for millennia. This knowledge contributes to climate science by offering observations and interpretations at a much finer spatial scale with considerable temporal depth and by highlighting elements that may not be considered by climate scientists" (8). In this example, TEK is a body of knowledge, or archive, waiting to be picked up by climate science. TEK is conceived as an archive that is continually updated or an archive of a society that no longer exists, yet biologists or ecologists can nonetheless find the knowledge and incorporate it into their research.

The assumption that TEK is a basic body of knowledge is often accompanied by the idea that elements of a society's worldview are an intimate dimension of its TEK system. Berkes, for example, defines TEK as "a cumulative body of knowledge, practice and belief, evolving by adaptive processes and handed down through generations by cultural transmission, about the relationship of living things (including humans) with one another and with their environment" (Berkes 1999, 8; see also Gadgil et al. 1993, 151). This definition situates TEK as a body of "knowledge, practice and belief" inspired by a particular worldview and bioregion. It is interwoven with a society's cultural fabric. Here, TEK is not just an archive, but a part of what members of a particular culture think, believe and do. It is situated knowledge.

The definition of TEK as a situated body of knowledge is found in policy documents. For example, the Natural Resources Conservation Service (NRCS) published Indigenous Stewardship Methods and NRCS, which aims to guide NRCS staff to work better with tribes. TEK is seen as bound up with "indigenous stewardship method," which is defined as the "ecologically sustainable use of natural resources within their capacity to sustain natural processes." Indigenous stewardship method (ISM) is possibly a 
...subset of Traditional Ecological Knowledge (TEK), in which indigenous peoples acquired the knowledge base over hundreds of years through direct experience and contact with the environment. ISM is the physical, spiritual, mental, emotional, and intuitive relationship of indigenous peoples with all aspects and elements of their environment.

These relationships include, but are not limited to, a combination of knowledge, experience, tradition, places, locality, all living and nonliving things, skills, practices, theories, social strategies, moments, spirituality, history, heritage, and more; and may not be fully embraced by people who fail to understand all those dimensions (Leonetti 2010, 13).

In this definition, TEK is considered a knowledge "base," or body of knowledge, though one embedded within multiple relationships among living beings, non-living things, and the environment. The passage above also raises a question concerning the degree that outsiders will be able to respect or comprehend a TEK system. But the purpose of the NRCS guide is to advance a set of best practices and principles so that NRCS staff can begin to work with communities for whom TEK forms a significant dimension of their lifeways.

An implication of definitions based on the assumption that TEK is a body of knowledge is that TEK can be picked up and used by scientists or agency staff. Each of the policy documents just cited involves the idea that TEK can be gleaned from the communities who have it, either through historical research or working with actual communities, and can then be incorporated into the environmental governance of non-indigenous institutions like those of the United Nations or U.S. Department of Agriculture. So the assumption about knowledge mobilization is that TEK, no matter what the society, is "something" that can be seen as archival. With some effort, it can be interpreted for use in different contexts, especially science policy contexts, that is, contexts where there is a given role for scientific information in environmental governance.

Some indigenous scientists, in particular, have offered definitions of TEK that resist the assumption that it is mainly a body of knowledge. McGregor, for example, argues that TEK involves the relationships between "knowledge, people, and all Creation (the 'natural' world as well as the spiritual)...TEK is viewed as the process of participating (a verb) fully and responsibly in such relationships, rather than specifically as the knowledge gained from such experiences. For Aboriginal people, TEK is not just about understanding relationships, it is the relationship with Creation. TEK is something one does" (McGregor 2004a,b, 2008, 145). For McGregor, TEK refers to the activities that people in indigenous societies are doing as part of their stewardship. It is not archival or body-like. To speak of a society's TEK is to speak of ongoing activities expressive of responsibilities.

The ideas of "fully" and "responsibly" suggest what in the field of philosophy is often called moral character or just character. Character refers to the idea that acting responsibly (and hence ethically) is a matter of possessing embodied traits like courage or respect that enable one to know the right thing to do in particular situations and to act in ways that maintain relations of balance within one's society. People who possess the character traits also possess the internal motivation to do what is right. Within a society's system of responsibilities, character refers to the particular traits that people acquire over many years (since childhood) in order to express responsibilities and balanced relationships in all that they do. Definitions like McGregor's see TEK systems as systems of responsibilities that cannot be detached from the character traits required to fulfill the moral demands of these systems.

Other native scholars have also emphasized the responsibilities and character dimensions of TEK. Pierotti and Wildcat see TEK as

... based in the knowledge that native societies existed under conditions of constant pressure on the resources upon which they depended, and that a means had to be found to convince communities and families to economize with regard to their use of natural resources... The connections that are a crucial aspect of TEK are based on a mixture of extraction, e.g. animals are taken as prey, combined with recognition of the inherent value and good of non-human lives. Traditional knowledge is based on the premise that humans should not view themselves as responsible for nature, i.e., we are not stewards of the nature world, but instead that we are a part of that world, no greater than any other part. In this way TEK deals largely with motivating humans to show respect for nonhumans (Pierotti and Wildcat 2000, 1336).

Pierotti and Wildcat see motivation, an important aspect of character, as a key component of TEK. They even suggest that terms like stewardship are not sufficient for describing the actual intimacies involved in relationships among living beings and non-living things on which TEK systems are based. As with McGregor, TEK is a doing, a full participation in a system of responsibilities needed for a society's flourishing. For both Pierotti and Wildcat and McGregor, great emphasis is placed on the idea that TEK is not knowledge about relationships but is the complete participation in the responsibilities. Similar definitions are found in the work of other indigenous scholars (Reo and Whyte 2012; Cajete 1999). 
TEK systems, then, are systems of responsibilities that arise from particular cosmological beliefs about the relationships between living beings and non-living things or humans and the natural world. There is an important implication for knowledge mobilization. TEK cannot be readily transferred to different contexts unless the people in the new context also learn the systems of responsibilities and character traits. Such learning entails complete cultural immersion. Thus, it could be problematic, on the system of responsibility assumption, to see TEK as something that could be incorporated by, for example, climate science. For climate science may not be used in a policy context that seeks to integrate the system of responsibilities of a particular indigenous people into its strategies for environmental governance.

The body of knowledge assumption and the system of responsibility assumption are different in important ways to the degree that they underlie various definitions of TEK. In terms of the former, TEK can be extracted from its society and fit into policy-relevant science. The gist goes something like this: climate science, for example, already fits within a particular policy context. This fit is not determined by indigenous peoples. That is, indigenous peoples are not active participants in the majority of decisions of governments, universities, and organizations about what funding programs to create for climate science and for selecting who should be on review panels. Moreover, TEK is not taken to be tied, in any important ways, to particular stewardship or management strategies. Insofar as climate science, in sticking with the last example, fits into a particular kind of understanding of management or adaptation, TEK is seen to contribute to that by being plugged into structures of scientific inquiry. But definitions based on the assumption that TEK is a system of responsibilities suggest that for TEK to be genuinely included, the people who participate fully in it must be at the table equally with non-indigenous scientists and policy makers. TEK is not a piece broken off of one of these strategies and applied to another. TEK just is the living environmental governance of indigenous peoples stemming directly from their cosmologies in relation to the environmental challenges they have faced over many generations.

The difference between the two assumptions can engender some difficulties in forming a consensus on the definition of TEK in terms of knowledge mobilization. One assumption seeks to fit TEK within established science policy decision-making frameworks, whereas the other seeks to change this framework in favor of greater participation by indigenous peoples.

\section{The relation between TEK and science}

TEK is also defined in ways that are based on assumptions about its relation to disciplines like forestry or climatology. The kind of assumption active in these definitions involves how TEK can be compared or contrasted to scientific disciplines (i.e., science). There are three assumptions covered in this subsection: (1) TEK and science should be seen as separate knowledge production systems. This distinction should never be collapsed. (2) TEK and science should be seen as twins, or two knowledge-bearing perspectives on the world that complement each other. (3) There is no basis for distinguishing TEK, or Indigenous knowledge, from science, and the term TEK or its synonyms should not be used. In all three of these views, there is a lot riding on how TEK and science are seen as related to each other because there are implications for what sorts of empirical authorities are deemed relevant for environmental governance.

The first version of this kind of assumption is that TEK and science are sufficiently different to warrant maintaining separate definitions. Proponents of this view believe that there are definite differences in the values and aspirations of science and those of TEK systems. El-Hani and Souza de Ferreira Bandeira exemplify this view. They use the term "indigenous knowledge" instead of TEK, though their use of this term is synonymous with TEK because they are talking about indigenous peoples' knowledge of the natural world and the relationships between living things and the environment. ${ }^{\mathrm{b}}$ They see Western modern science as "the most powerful way of producing naturalistic explanations of natural phenomena." Yet it is also the case that "there are plenty of different accounts of the world [i.e. indigenous knowledge] which are also powerful in their own ways" (2008, 756). They see indigenous knowledge as part of this latter grouping: these other accounts "are producing explanations about supernatural (or, maybe non-natural is a better term) beings and phenomena that are useful to several human cultures. And, in the face of natural phenomena, they are producing explanations that appeal to spiritual domains, going beyond naturalistic chains or networks of events" (2008, 756). The key to this difference, then, is that indigenous knowledge usually involves some account of non-natural beings whereas science always excludes these non-natural beings. This reflects some of the ideas of the previous section, where TEK is tied to spirituality.

To call something science, then, for El-Hani and Souza de Ferreira Bandeira, certain standards must be met. For example, science embodies values and skills such as "technical precision, control, creative genius, and explanatory power..." Quoting Siegel, they argue that science and indigenous knowledge could only be the same thing "if it could be cogently argued that some particular 'ethnic' science...offered compelling theories/predictions/explanations of natural phenomena. Could an animistic ethnic theory of volcanic activity and lava flow...provide the sort of explanation, prediction, grasp 
of relations among unobservables and between observables and unobservables, and depth of scientific understanding provided by Western science?" (El-Hani et al. 2008, 757; Siegel 1997, 100). According to this understanding, there are definite values and knowledgebearing capabilities of science that cannot be attributed to indigenous knowledge of the environment.

Indigenous knowledge, while it may produce important knowledge, does not do so in the ways that scientific disciplines do. This is, according to the authors, not a form of discrimination: "Notice that we are not saying that the way this community builds knowledge, the knowledge built, or the criteria employed to appraise cognitive statements are epistemically superior to any other body of approaches, ideas, statements, criteria. We are just saying that they are different, and should be kept different, for the sake of clarity about the nature of knowledge and the nature of science" (El-Hani and Souza de Ferreira Bandeira 2008, 758). In this assumption about indigenous knowledge (or TEK) and science, there are definite criteria, values, skills, and so on that science and TEK have, but there is not a lot of crossover. So TEK's supernatural and social aspects, respectfully so, exclude the possibility of the kind of rationality associated with science. Moreover, societies without computing capacities built into their TEK systems cannot value quantitative research in the same way that it is valued in natural sciences disciplines, nor can they engage in the same kind of research.

This first assumption, that TEK and science are fundamentally different, differs from the second assumption, which sees the former and the latter as two complementary perspectives on the environment that stem from complementary views on the world. The views are complementary because there is both crossover as well as gap filling. Kimmerer argues that

Traditional ecological knowledge refers to the knowledge, practice, and belief concerning the relationships of living beings to one another and to the physical environment, which is held by peoples in relatively nontechnical societies with a direct dependence upon local resources... It is born of long intimacy and attentiveness to a homeland and can arise wherever people are materially and spiritually integrated within their landscape. TEK is rational and reliable knowledge that has been developed through generations of intimate contact by native peoples with their lands (Kimmerer 2002, 431).

TEK and science, for Kimmerer, can be seen as having a complementary relation to each other. Indeed, TEK can be seen as the "intellectual twin to science," a term she borrows from Deloria (433). Kimmerer claims that TEK exists "in parallel to Western science" (433). She claims that "Both knowledge systems yield detailed empirical information of natural phenomena and relationships among ecosystem components." This can include "predictive power," overlapping biological information, "detailed empirical knowledge of population biology, resource assessment and monitoring, successional dynamics, patterns of fluctuation in climate and resources, species interactions, ethnotaxonomy, sustainable harvesting, and adaptive management and manipulation of disturbance regimes..." (Kimmerer 2002, 433). Yet TEK differs from science for Kimmerer in important ways:

TEK observations tend to be qualitative, and they create a diachronic database, that is, a record of observations from a single locale over a long time period. The National Science Foundation, in its support of the Long-Term Ecological Research program, has validated the importance of such continuous data. In TEK, the observers tend to be the resource users themselves, for example, hunters, fishers, and gatherers whose harvesting success is inextricably linked to the quality and reliability of their ecological observations. In contrast, scientific observations made by a small group of professionals tend to be quantitative and often represent synchronic data or simultaneous observations from a wide range of sites, which frequently lack the long-term perspective of TEK... Western science is conducted in academic culture in which nature is viewed strictly objectively... TEK is woven into and is inseparable from the social and spiritual contexts of the culture... TEK may also extend its explanatory power beyond the strictly empirical, where science cannot go... In indigenous science, nature is subject, not object. . . Embraced as an equal partner to the power of Western science, TEK offers not only important biological insights but a cultural framework for environmental problem solving that incorporates human values (Kimmerer 2002, 433-434).

Here, then, for Kimmerer, TEK and science are two parallel, complementary perspectives on the environment and natural resources. They go hand in hand. Different from the first assumption, Kimmerer has no problem using concepts like "prediction" or "rational" with respect to TEK, nor stating straightforwardly that techniques in TEK systems fit well with and are valued by science. She also shows that the influence of culture in TEK systems could be considered beneficial to science. Though she admits differences, they are not the stark differences that are maintained in the first assumption. For Kimmerer, then, knowledge production that fails to incorporate both TEK systems and the relevant sciences would be missing key perspectives on the world. Instead of saying that they are valuable in their 
own ways (as in the first assumption), Kimmerer is saying that they are valuable together. Both knowledge production systems can learn a great deal from each other.

A third assumption diverges, in general, from the first two by desiring to dispense altogether with the pursuit of defining differences and complementarities between TEK systems and science. That is, in this assumption, there is really no use in even talking theoretically about a distinction between TEK and science because at the end of the day they are faces of the same phenomena: the pursuit of usable knowledge by human societies. Agrawal, for example, argues that

The attempt to create distinctions in terms of indigenous and western is potentially ridiculous. It makes much more sense. . . to talk about multiple domains and types of knowledges, with differing logics and epistemologies. Somewhat contradictorily, but inescapably so, the same knowledge can be classified one way or the other depending on the interests it serves, the purposes for which it is harnessed, or the manner in which it is generated... [A]nchored unavoidably in institutional origins and moorings, knowledge can only be useful. But it is useful to particular peoples. Specific strategies for protecting, systematizing and disseminating knowledge will differentially benefit different social groups and individuals. The recognition of this simple truism is obscured by the confounding labels of indigenous and western. It is only when we move away from the sterile dichotomy between indigenous and western, when we begin to recognize intra-group differentiation; and when we seek out bridges across the constructed chasm between the traditional and the scientific, that we will initiate a productive dialogue to safeguard the interests of those who are disadvantaged (Agrawal 1995, 433).

This third view, then, suggests that to use terms like indigenous knowledge or TEK or Western science obscures several important points. First, TEK and science are all value-laden knowledge systems. The literature in social studies of science shows multiple ways in which science is guided by particular values and even associated with spirituality (Biagioli 1999; Turnbull 2000). Second, there is no reason why the criteria and values attributed to various sciences cannot also be those of various TEK systems. Moreover, by "intra-group" differentiation, Agrawal points out that there are few indigenous people who rely on a single, homogenous TEK system; rather their knowledge system has changed and they likely also rely on different scientific disciplines as well. Examples of this abound, like Gupta's 1998 study of how rural farmers in India engage in hybrid agricultural practices that mix Western scientific and traditional knowledge systems (Gupta 1998). Or Watson-Verran and Turnbull discuss how Western science is composed of heterogeneous elements (WatsonVerran and Turnbull 1995).

Agrawal's position is based on the idea that every society has some sort of knowledge system, which may be a patchwork of systems with multiple origins (e.g., European, indigenous). There is no such thing as a knowledge system that is not guided by people's interpretations of the challenges that they face. And interpretations are influenced by worldviews. There is no such thing as a knowledge system that is more neutral than any other. In the case of scientific disciplines, values of objectivity are based on cosmological assumptions about there being subjects and objects in the world and which beings, entities, and phenomena fall under one or the other. A science based on such assumptions may be of limited use to a society that does not carve up reality in this way. But on the other hand, such a society may have great use for this kind of information. Context is key. Agrawal's assumption speaks to the situation that many indigenous peoples encounter in the world. They need reliable information for the environmental governance challenges they face. And they are likely in the position to draw from many sources of knowledge. What knowledge they can use depends on how suitable different forms of knowledge are for their purposes. Whether forms of knowledge are indigenous or not does not really matter in the end. Some indigenous peoples may be served perfectly well by disciplines like biology as the basis of their environmental governance strategies. So the implication is that terms like TEK or indigenous knowledge are not very useful and may even waste our time. We should focus more on figuring out what knowledge systems best serve the needs of particular communities and how to realize them in practice.

As with knowledge mobilization, the distinction between TEK and science does not generate many easy options for consensus on how to define the two in relation to each other. First, the view that TEK and science must be labeled as such, and kept distinct, misses the realities of indigenous environmental governance today. There is no reason why any so-called TEK system cannot embrace similar empirical values that are found commonly in various scientific disciplines. One who adopts this assumption would perhaps have to consider dropping it were one to concede that certain values and criteria are not exclusive to science. So it would be tricky for one to accept certain parts of both the first and second assumptions. Moreover, contemporary tribal environmental governance involves examples of institutions that are guided by TEK but that use technologies and methods that originate from nontribal scientific disciplines (Woodard 2005). Even examples of practices like hunting show that TEK systems are adaptive in their adoption of technologies (Reo and Whyte 
2012). In these cases, it is hard to imagine a rigid separation between TEK and science and technology because TEK systems can incorporate scientific techniques. Advocates of the third assumption, of course, would find it fairly difficult to accept the first two assumptions because they invoke a distinction between TEK and science too readily. Agrawal's conclusion is that the term TEK must be dispensed with altogether, as must particularly loaded conceptions of science. So the first assumption seeks to maintain a rigid separation in definitions; the second assumption seeks a definition that reveals complementarity; the third assumption can be seen as desiring to dispense with the business of the first two assumptions altogether.

It is somewhat hard to see people who hold any of these three assumptions coming to a consensus definition. Combined with differences regarding knowledge mobilization, it is even harder to see there ever being a single definition acceptable to all stakeholders. But I want to offer another, fruitful approach to coming to an understanding of TEK that can advance environmental governance even as we discuss and disagree on the assumptions underlying various definitions. My approach is different from Agrawal's insofar as I do not see the need to dispense with the term TEK. While Agrawal comes close to my understanding of the difficulties in defining TEK, he does not draw the only possible conclusion from accepting the reality of these difficulties. The fact that a term is defined in ways that are problematic and subject to deep differences does not entail that it has no use. Rather, this fact motivates us to consider whether the term, given all its potential definitions and confusing dimensions, has a proper role to play in advancing collaborative environmental governance. I turn to this topic in the next subsection.

\section{The role of TEK as a collaborative concept}

This subsection shows why TEK should be considered as a collaborative concept that bridges cross-cultural and cross-situational divides. To make this case, the initial pages of this section focus on the environmental governance situations in which many tribes are embedded, and I use the term co-management as an example of this. I then move on to define what a collaborative concept is and how this relates to the discussion of TEK I have been building so far in this paper. In this sense, the initial pages of this section take a slight detour before returning to the concept of TEK.

Regardless of how TEK can be defined, what is the role of the concept of TEK, in the first place, in the world of environmental governance? The world of environmental governance, here, involves relations between environmental governance institutions associated with and responsible to indigenous peoples, like tribal natural resources departments and those regulating indigenous hunting practices, and governance institutions associated with states and subnational units like the U.S. Forest Service and Environment Canada. All of these institutions have evolved ways of doing things out of histories in which the very idea of indigenous environmental governance was overtly and subtly marginalized. Times are changing, and greater respect is accorded to indigenous peoples through international, federal, and local law and policy. These changes create opportunities for indigenous peoples to work collaboratively with non-indigenous peoples, instead of against them or in secrecy from them (covertly). Indigenous peoples can begin to build institutions of environmental governance that are integrated with non-indigenous institutions in ways that benefit indigenous communities and respect the stewardship goals of their worldviews.

But institution building of this kind is always a work in progress because of cross-cultural and cross-situational divides. Cross-cultural divides are simply the differences in worldview, language, lifestyle, and so on that obtain between indigenous and non-indigenous populations. For example, an indigenous people may see the goal of restoring a native fish species as rekindling the relationship between that species and humans living in the region, whereas a non-indigenous population may see restoration of the same species as a matter of achieving certain population numbers conducive to a recreational outcome like increasing tourism in the region. Cross-cultural divides can also have an intra-group dimension to them, as there may be differences in beliefs about building relationships with a species in an indigenous community and territory, for example. Cross-situational divides are differences in capacities for environmental governance. For example, an indigenous people may have access to fewer financial resources than the neighboring state or province, have limited political control over the entire region where its members live, and have less representation in national decision-making than representatives of the neighboring state or province. Cross-cultural and cross-situational divides make collaboration challenging. It may be hard for federal institutions to incorporate indigenous people's goals within their policy frameworks. It may be frustrating to work across institutions with different bureaucratic capabilities.

Since the possibility of meaningful collaboration is a relatively recent turn of events, there is yet to be perfect guidance about how collaboration that bridges cross-cultural and cross-situational divides ought to be done. There are cases of success and cases of failure. And there is still a lot to be learned regarding whether the lessons from cases of success can simply be transferred over to other contexts. Caught in this predicament, there are a host of concepts that are being debated as concepts that facilitate or discourage genuine collaboration. For example, the concept of co-management has been used to suggest a possible route to cooperative environmental and natural resources 
governance (Goetze 2005). ${ }^{\mathrm{c}}$ Co-management invokes the idea of joint political relationships between indigenous and non-indigenous institutions that work together according to standards of fairness to govern particular areas and bkresources. Standards of fairness include norms like equal representation and voting rights. The concept of comanagement is the basis of actual co-management boards and committees that are composed of indigenous and nonindigenous participants and that are responsible for managing a fishery or forested area, or particular species, like a caribou population. Indigenous and non-indigenous institutions often rely on the term co-management as part of a shared language for bridging cross-cultural and crosssituation divides. However, there is also dialogue on how the concept of co-management can be taken the wrong way and provide insufficient guidance for collaboration. It is often argued that the concept co-management implies that the nation-state's (e.g., Canada, U.S.) vision for environmental governance is used to evaluate the collaborative efforts between indigenous and non-indigenous institutions. This is because the term "management" can connote a non-indigenous view of the appropriate relationship among humans, other living beings, and the environment. This term can slant the meaning of co-management so that non-indigenous participants in a co-management board, for example, come in with expectations that their assumptions about "management" should be prioritized and may not listen to their indigenous colleagues. The term, then, can have the effect of silencing genuine negotiation of cross-cultural and cross-situational differences.

Instead, the concept of co-existence is offered (McGregor 2004b), which suggests the importance of balancing indigenous and non-indigenous aspirations of governance into the evaluation of collaboration. In this case, one might be inclined to think cynically that it is all about labels. But there is much more going on than preferences about labels. We need to consider the role played by concepts like co-management and co-existence in facilitating or discouraging collaboration. People who reject the concept of comanagement based on the contexts they are familiar with see in it problematic assumptions about how indigenous and non-indigenous institutions should work together. Non-indigenous people may not see how the concept of co-management might encourage these assumptions, even though, perhaps, co-management is the preferred concept in some contexts. Those who reject the concept of comanagement and wish to replace it with the concept of coexistence are inviting non-indigenous people to learn more about cross-cultural and cross-situational divides. This is the role that concepts like co-management and coexistence play. The concept of co-existence does not in itself contain enough meaning for non-indigenous persons to suggest in advance exactly how a collaborative process should play out. What proponents of co-existence are saying is that there is much learning to do. The concept of co-existence suggests a very different possibility for collaboration than what non-indigenous peoples may be used to. Work on co-existence expresses an invitation to learn about cross-cultural and cross-situational divides so as to achieve better collaborations in particular contexts.

There are two important points here regarding the role of these concepts. First, co-management and co-existence are invoked, for better or worse, by many different institutions in contexts where they are trying to collaborate across cross-cultural and cross-situational divides. Second, the example of co-existence I gave is an example of how some people seek to use concepts to improve collaboration by inviting people to consider alternatives that may not have been on their conceptual radar before. The concept of TEK and its synonyms plays a somewhat analogous role to the term co-existence. As in the first point, various definitions of TEK are used in collaborative contexts, for better or worse. As in the second point, those who bring new definitions of TEK into dialogue are inviting others to consider new possibilities for thinking about the function of knowledge systems in environmental governance.

However, we need to be precise about what this meansbecause I am not arguing that there is a single definition of TEK that can count for all. This is impossible. TEK, no matter how it is defined, is not adequate for any indigenous community. The English articulation, TEK, is not an indigenous word or concept, and it is likely not used within very many communities unto themselves. The terms traditional and ecological are awkward. Traditional can have the effect of putting knowledge in the past, whereas TEK is often supposed to mean contemporary knowledge. Ecological aligns TEK with a particular discipline, whereas TEK refers to knowledge that does not stem from that discipline. Terms like indigenous knowledge and native science are similarly awkward when we unpack what associations and dissociations they may imply. Moreover, there may be many contexts where an indigenous people does see the concept as referring to accumulated observations, for example, or contexts where TEK is viewed as a Western construct irrelevant to environmental governance. There are likely other contexts where TEK needs to refer to systems of responsibilities. There are multiple possible scenarios. The concept of TEK cannot possibly do justice to the knowledge systems and articulations of knowledge systems belonging to the thousands of indigenous peoples. TEK is also not a concept that was an integral part of the education of most ecologists or foresters, nor is it a concept that has existed for a long time in the federal policies of a nationstate. This does not mean, though, that the concept should be dispensed with. Non-indigenous peoples may be equally uncomfortable with referring to something they are not familiar with as science or linked with a particular scientific discipline. It may be no easier for them to change out terms 
like TEK with even more general terms like Agrawal's "usable knowledge."d

Thus, whenever the concept of TEK is invoked, the role that it plays is to suggest that indigenous communities may approach the very question of the nature of knowledge and how it relates to environmental and natural resource governance rather differently than disciplines like ecology or biology and the policy contexts in which they are used. By, "rather differently," I do not mean in some sense that applies to all communities. For example, there may be some indigenous communities that invoke TEK to mean a radically different cultural paradigm, one in which it is not appropriate to speak of knowledge as distinct from practice or belief. But other indigenous communities who live in different regions because of historical removal may invoke TEK to stand for the values that they believe disciplines like ecology should serve, even if they lack intimate experiences with the environment they currently inhabit. Yet other communities might use TEK to suggest different ways in which multiple empirical techniques for gathering knowledge, from hunters' observations to scientific field methods, can be used in harmony. TEK could also refer to ideas about how elders should be involved in the design and peer review of research in tribal environmental departments that collect their own data about the environment and the condition of natural resources. There are many more scenarios, of course. These scenarios indicate the diversity of how people, at a philosophical level, think about the meaning of knowledge in relation to their lives. And their thinking arises from multiple cultural, historical, global, social, and personal sources.

The significance of this point is that when the concept of TEK is used, it really points to the possibility that there are cross-cultural and cross-situational divides that make it so that non-indigenous parties cannot expect their own assumptions to apply to indigenous contexts. The concept of TEK should be invoked to invite nonindigenous parties to learn more about how particular indigenous communities approach fundamental questions of the nature of knowledge and how it fits into their visions of environmental governance. This invitation is not one that promises easy answers. Rather, it is an invitation to become a part of a long term process whereby cross-cultural and cross-situation divides are better bridged through mutual respect and learning, and relationships among collaborators are given the opportunity to mature. Examples of long term processes include "the way of peace" used among indigenous and non-indigenous participants in the Ontario Model Forest (Holmes et al. 2002; Story and Lickers 1997). There are many other examples. We need not only be concerned with striking the right definition of TEK. Rather, we need to cultivate attitudes of awareness that the concept of TEK plays a role as a collaborative concept, which is what I call a concept that invites people to engage in a process of respectful learning about significant differences. ${ }^{\mathrm{e}}$

\section{Conclusions}

TEK and its synonyms indigenous knowledge and native science have been defined mainly based on two kinds of assumptions: how knowledge is to be mobilized and what TEK's relation to science is. The different assumptions make it tricky to come to a consensus definition that satisfies all stakeholders. This makes us interrogate what the role of TEK is in a world of relationships among different institutions of environmental governance for whom TEK is an issue. TEK must play the role of inviting crosscultural and cross-situational learning for indigenous and non-indigenous policy makers, natural resource managers, scientists, activists, elders, and youth.

An important implication of this is that science and policy literatures that invoke TEK should discuss it as a collaborative concept. That is, care must be taken to show that the concept invites participation to a long term process of mutually respectful learning. And more effort needs to be taken to understand what these processes should look like. Already, of course, there is work that exemplifies this interpretation of TEK (Barnhardt 2005; Ross et al. 2010). Yet the point has not been brought out that TEK is playing the role of a collaborative concept in this work. This point should figure more in natural resources and policy literatures. Differences over the meaning of TEK should be seen as invitations to learn more in circumstances where the possibility of genuine collaboration is a relatively recent development.

\section{Endnotes}

${ }^{a}$ Indigenous peoples refer to the pre-invasion inhabitants of lands now dominated by others, examples being the Maori in New Zealand or the Anishinaabe in the United States and Canada (Anaya 2004).

${ }^{\mathrm{b}} \mathrm{I}$ will use the term indigenous knowledge specifically when I refer to the work of these authors and shift back to the term TEK for my own analysis. My analysis of Agrawal, later on in the same section, will also use indigenous knowledge when referring specifically to his work and TEK when referring to my own analysis.

${ }^{\mathrm{C}}$ Other collaborative literature includes Fortmann 2008 and Colwell-Chanthaphonh and Ferguson 2008.

${ }^{\mathrm{d}}$ Agrawal too has considered the role of the concept of TEK in cross-cultural and cross-situational collaboration. He argues that

... it is possibly the case that advocates of indigenous knowledge find in the term a particularly potent way to summarize and invoke many of their concerns and hopes about peoples, livelihoods, life styles, and 
resource systems they view as disappearing. The phrase evokes embattled ways of living-in-the-world that real economic, social and political pressures are nudging and frog-marching toward further marginalization and oblivion. Because the indigenous/ scientific division of knowledge effectively represents durable underlying social confrontations, the study and defense of indigenous knowledge continues to attract attention. Indeed, even as one questions the need to contrast indigenous and scientific knowledges, one underscores this contrast-in the very use of the contrasting adjectives. Indigenous knowledge is here to stay, even if what it represents is forever and always disappearing (Agrawal 2009, 158).

I hope to articulate in this paper that there are far more reasons why people invoke concepts like TEK or indigenous knowledge than what Agrawal states.

${ }^{\mathrm{e}}$ Collaborative concepts also differ from boundary objects (Star and Griesemer 1989). Boundary objects are commonly shared by diverse stakeholders and serve to coordinate their actions despite different interests. Collaborative concepts are invitations to learn more, which suggest the need for a long term process of mutually respectful learning.

\section{Competing interests}

The author declares that there are no competing interests.

\section{Acknowledgments}

I wish to thank Kristie Dotson, Michael O'Rourke, Nicholas Reo, and the anonymous reviewers for their insightful comments on this paper.

Received: 11 December 2012 Accepted: 17 January 2013

Published: 5 April 2013

\section{References}

Agrawal A (1995) Dismantling the divide between indigenous and scientific knowledge. Dev Change 26(3):413-439

Agrawal A (2009) Why "indigenous" knowledge? J R Soc N Z 39(4):157-158

Anaya SJ (2004) Indigenous peoples in international law, 2nd edition. Oxford University Press, New York

Barnhardt R (2005) Indigenous knowledge systems and Alaska Native ways of knowing. Anthropol Ed Q 36(1):8-23

Berkes F (1999) Sacred ecology: traditional ecological knowledge and resource management. Taylor \& Francis, Philadelphia

Biagioli M (1999) The science studies reader. Routledge, New York

Brokensha DW, Warren DM, Werner O (1980) Indigenous knowledge systems and development. University Press of America, Washington DC

Cajete G (1999) Native science: natural laws of interdependence. Clear Light Books, Santa Fe, NM

Colwell-Chanthaphonh JS, Ferguson TJ (2008) Collaboration in archaeological practice: engaging descendant communities. AltaMira, Lanham, MD

Eisner WR, Cuomo CJ, Hinkel KM, Jones BM, Brower S, Ronald H (2009) Advancing Landscape Change Research through the Incorporation of Iñupiaq Knowledge. Arctic 62(4):429-442

El-Hani C, de Ferreira S, Bandeira F (2008) Valuing indigenous knowledge: to call it "science" will not help. Cult Stud Sci Educ 3(3):751-779. doi:10.1007/ s11422-008-9129-6

Ellen R (2000) Indigenous environmental knowledge and its transformations: critical anthropological perspectives, vol 5. Routledge, New York

Fortmann $L$ (2008) Participatory research in conservation and rural livelihoods: Doing science together, vol 3. Wiley-Blackwell, Hoboken
Gadgil M, Berkes F, Folke C (1993) Indigenous knowledge for biodiversity conservation. Ambio 22(2/3):151-156

Goetze TC (2005) Empowered co-management: towards power-sharing and indigenous rights in Clayoquot Sound, BC. Anthropologica 47(2):247-265

Gupta A (1998) Postcolonial developments: agriculture in the making of modern India. Duke University Press, Durham, NC

Harding S (1998) Is science multicultural?: postcolonialisms, feminisms, and epistemologies. Indiana University Press, Bloomington

Harding S (2011) The postcolonial science and technology studies reader. Duke University Press, Durham, NC

Harris G (ed) (2011) Northwest Forest Plan-the first 15 years [1994-2008]: effectiveness of the federal-tribal relationship. Tech. Paper R6-RPM-TP-012011. U.S. Department of Agriculture, Forest Service, Pacific Northwest Region, Portland

Holmes E, Lickers H, Barkley B (2002) A critical assessment of ten years of on-the -ground sustainable forestry in eastern Ontario's settled landscape. For Chron 78(5):643-647

Houde N (2007) The six faces of traditional ecological knowledge: challenges and opportunities for Canadian co-management arrangements. Ecol Soc 12(2):34

Huntington $\mathrm{H}$ (2000) Using traditional ecological knowledge in science: methods and applications. Ecol Appl 10(5):1270-1274

Kimmerer R (2002) Weaving traditional ecological knowledge into biological education:7 a call to action. Bioscience 52(5):432-438. doi:10.1641/0006-3568 (2002)052[0432:WTEKIB]2.0.CO;2

Kimmerer $R$, Lake $F$ (2001) The role of indigenous burning in land management. J For 99(11):36-41

Kofinas GP (2005) Caribou hunters and researchers at the co-management interface: emergent dilemmas and the dynamics of legitimacy in power sharing. Anthropologica 47(2):179-196

Leonetti C (2010) Indigenous stewardship methods and NRCS conservation practices. United States Department of Agriculture. Natural Resources Conservation Service, Anchorage

McGregor D (2004a) Coming full circle: indigenous knowledge, environment, and our future. Am Indian Q 28(3\&4):385-410

McGregor D (2004b) Traditional ecological knowledge and sustainable development: towards coexistence. In: Blaser M, Feit HA, McRae G (ed) In the way of development: indigenous peoples, life projects and globalization. Zed/IDRC, Ottawa

McGregor D (2008) Linking traditional ecological knowledge and western science: aboriginal perspectives from the 2000 State of the Lakes Ecosystem Conference. Can J Nativ Stud XXVIII(1):139-158

Nadasdy P (1999) The politics of TEK: power and the "integration" of knowledge. Arct Anthropol 36(1-2):1-18

Nakashima DJ (1993) Astute observers on the sea ice edge: Inuit knowledge as a basis for arctic co-management. In: Inglis J (ed) Traditional ecological knoweldge: concepts and cases. International Program on Traditional Ecological Knowledge and International Development Research Centre, Ottawa, pp 99-110

Nakashima DJ, Galloway McLean K, Thulstrup HD, Ramos Castillo A, Rubis JT (2012) Weathering uncertainty: traditional knowledge for climate change assessment and adaptation. UNESCO and Darwin, UNU, Paris

Pierotti R, Wildcat D (2000) Traditional ecological knowledge: the third alternative. Ecol Appl 10(5):1333-1340

Reo N, Whyte K (2012) Hunting and morality as elements of traditional ecological knowledge. Hum Ecol 40(1):15-27. doi:10.1007/s10745-011-9448-1

Ross A, Sherman R, Snodgrass JG, Delcore HD (2010) Indigenous peoples and the collaborative stewardship of nature: knowledge binds and institutional conflicts. Left Coast Press, Walnut Creek, CA

Salmon E (1996) Decolonizing our voices. Winds Change 11(3):70-72

Siegel H (1997) Science education: multicultural and universal. Interchange 28 (2):97-108

Star SL, Griesemer JR (1989) Institutional ecology, 'Translations' and boundary objects: amateurs and professionals in Berkeley's museum of vertebrate zoology, 1907-39. Soc Stud Sci 19(3):387-420

Story P, Lickers F (1997) Partnership building for sustainable development: a First Nations perspective from Ontario. J Sustain For 4(3-4):149-162

Turnbull D (2000) Masons, tricksters and cartographers: comparative studies in the sociology of scientific and indigenous knowledge. Taylor \& Francis, Philadelphia

UNEP (1998) Report of the fourth meeting of the parties to the convention on biodiversity. UNEP/CBD/COP/, Nairobi, Kenya 
Voggesser G (2010) The tribal path forward: confronting climate change and conserving nature. Wildlife Prof 4(4):24-30

Warren DM, Slikkerveer $\amalg$, Brokensha D (1995) The cultural dimension of development: indigenous knowledge systems. Intermediate Technology Publications, London

Watson-Verran H, Turnbull D (1995) Science and other indigenous knowledge systems. In: Jasanoff S, Markle G, Petersen J, Pinch T (ed) Handbook of science and technology studies. Sage, London, pp 115-139

Wildcat DR (2009) Red alert! Saving the planet with indigenous knowledge (Speaker's corner). Fulcrum, Golden, CO

Woodard S (2005) Blending science and tradition in the Arctic. Indian Country Today, 590 Madison Avenue, New York. 10022

doi:10.1186/2192-1709-2-7

Cite this article as: Whyte: On the role of traditional ecological

knowledge as a collaborative concept: a philosophical study. Ecological Processes 2013 2:7.

\section{Submit your manuscript to a SpringerOpen ${ }^{\circ}$} journal and benefit from:

- Convenient online submission

- Rigorous peer review

- Immediate publication on acceptance

- Open access: articles freely available online

- High visibility within the field

- Retaining the copyright to your article

Submit your next manuscript at $\gg$ springeropen.com 